\title{
Effects of hyperbaric oxygen and iloprost on intestinal ischemia-reperfusion induced acute lung injury
}

\author{
Yeliz Yilmaz', Levent Tumkaya² \\ 'Department of General Surgery, Izmir Katip Celebi University, Ataturk Training and Research Hospital, Izmir, Turkey \\ ${ }^{2}$ Department of Histology and Embryology, Recep Tayyip Erdogan University, Faculty of Medicine, Rize, Turkey
}

\begin{abstract}
Purpose: To research the effects of iloprost (IL) and hyperbaric oxygen (HBO) combination treatment on lung injury and on tumor necrosis factor alpha (TNF- $\alpha$ ), myeloperoxidase (MPO), malondialdehyde (MDA), and soluble intercellular adhesion molecule-1 (sICAM-1) levels after tissue or organ ischemia-reperfusion, and on ischemia-reperfusion induced lung neutrophil sequestration.

Methods: Forty white New Zealand rabbits were assigned randomly into 5 groups: HBO, IL, HBO+IL, control, and sham groups. TNF- $\alpha$ values were checked before ischemia, in the 1st hour of ischemia and in the 1st and 4 th hours of reperfusion, also at the end of reperfusion period, plasma and tissue MPO values, MDA values, and sICAM-1 levels were detected. After sacrifice, the degree of lung injury was determined by histopathological examination.

Results: Compared to the control group all therapy groups showed a drastically meaningful reduction in TNF- $\alpha$ increase in 1, 2, and 4 hours. Plasma and lung MDA, MPO, and sICAM-1 levels were significantly lower in IL, HBO, HBO+IL, and sham groups compared with the control group. IL and/or HBO suppressed MDA and MPO increase in the lung tissue and in plasma. Additionally, histopathological score was significantly lower in $\mathrm{HBO}, \mathrm{IL}, \mathrm{HBO}+\mathrm{IL}$, and sham groups than that of the control group.

Conclusion: Both HBO and IL therapy have a beneficial effect by causing a meaningful reduction in TNF- $\alpha$ production, MPO, MDA, sICAM-1 levels and pulmonary neutrophil sequestration; which play a role, especially, in ischemia reperfusion induced lung damage.
\end{abstract}

[Ann Surg Treat Res 2019;96(1):34-40]

Key Words: Hyperbaric oxygenation, Iloprost, Tumor necrosis factor-alpha, Reperfusion injury

\section{INTRODUCTION}

Remote lung damage is of main significance after ischemiareperfusion (IR) period of intestinal and carry major importance $[1,2]$. Mediators and metabolites distributed from injured muscles (e.g., interleukin [IL]-1 $\beta$, IL-6, IL-8, tumor necrosis factor [TNF]- $\alpha$, and elastase- $\alpha 1$-antitrypsins) enhance the quantity of polymorphonuclear leukocytes in circulation [3]. These circulating cells in the lung tissue cause microvascular changes mediated by the neutrophils. Also, during reperfusion, skeletal muscle free radical formation leads to additional lung damage [1-3]. Raised plasma reactive oxygen species concentrations might induce oxidative damage in the capillary membranes of the lung by the peroxidation of lipids. Simultaneously, a defensive tissue response is provoked by inflammation, augmenting heat shock proteins expression. As a result, the IR leads to pulmonary edema by pulmonary hypertension, vasoconstriction, and increase in permeability of the alveolar membrane [4,5].

The advantageous results of hyperbaric oxygen (HBO)
Received May 24, 2018, Revised August 9, 2018,

Accepted August 29, 2018

\section{Corresponding Author: Yeliz Yilmaz}

Department of General Surgery, Izmir Katip Celebi University, Ataturk Training and Research Hospital, Basın Sitesi 35360 Izmir, Turkey

Tel: +90-532-592-2370, Fax: +90-232-243-1530

E-mail: dryelizyilmaz@yahoo.com

ORCID code: https://orcid.org/0000-0003-1811-122X
Copyright (C) 2019, the Korean Surgical Society

(c) Annals of Surgical Treatment and Research is an Open Access Journal. All articles are distributed under the terms of the Creative Commons Attribution NonCommercial License (http://creativecommons.org/licenses/by-nc/4.0/) which permits unrestricted non-commercial use, distribution, and reproduction in any medium, provided the original work is properly cited. 
might be attributed to its capability to decrease activation of neutrophils and IR injury sequestration. In experimental studies on animals, HBO has been shown to reduce ischemic edema, increase aerobic metabolism to maintain energy-rich complexes, decrease vein neutrophil adhesion and restrain ongoing neighboring arteriolar ischemic muscle vasoconstriction [68]. HBO diminishes rat lung neutrophil sequestration with IR injury and suppress inflammatory processes [6-9]. Iloprost (IL) is a prostacyclin analog and has been used in animal studies for its neuroprotective effect. IL mimics prostacyclin by inhibiting aggregation of platelets, cytoprotection, and vasodilatation [10]. IL pretreatment reduces injury of the lung following ischemia $[5,6]$.

The present study aimed to evaluate the effects of combination therapy of $\mathrm{HBO}$ and IL on lung damage after tissue or organ IR, on serum TNF- $\alpha$, myeloperoxidase (MPO), malondialdehyde (MDA) and soluble inter-cellular adhesion molecule-1 (sICAM-1) levels, and on IR induced neutrophil sequestration.

\section{METHODS}

\section{Study design}

Animal care complied with the Principles of Laboratory Animal Care as formulated by the National Society for Medical Research and the Guide for the Care and Use of Laboratory Animals (National Institutes for Health publication No. 5377-3, 1996). The experimental study was approved by the Animal Research Ethics Committee of Recep Tayyip Erdogan University Medical Faculty (Institution Review Board: 2015/45). All animals were given 5 days of adaptation to their environment prior to experiments. Room temperature was kept between $26^{\circ} \mathrm{C}$ to $28^{\circ} \mathrm{C}$.

Forty New Zealand white male rabbits, weighing $2.3-3.2 \mathrm{~kg}$ (mean, $2.8 \mathrm{~kg}$ ), were randomly allocated into 1 of 5 study groups each containing eight animals. The HBO group received a single session of HBO treatment, the IL group received $25 \mathrm{ng} / \mathrm{kg} / \mathrm{min}$ infusion of IL; the HBO + IL group received both $\mathrm{HBO}$ and IL; the control (IR) group received only $0.9 \%$ saline; and the fifth group was the sham group. $\mathrm{HBO}$ treatment and IL infusion were administrated during 60 minutes of ischemia and 60 minutes of reperfusion in the treatment groups.

\section{Anesthesia and surgical technique}

Initial anesthesia was achieved with intramuscular ketamine $(50 \mathrm{mg} / \mathrm{kg})$ and xylazine $(5 \mathrm{mg} / \mathrm{kg})$ without endotracheal intubation; then followed by $25 \mathrm{mg} / \mathrm{kg}$ fractionally in order to allow the animals to have spontaneous respiration. Body temperature was maintained close to $38^{\circ} \mathrm{C}$ using a thermostatically controlled heated operation table. All animals received a similar volume of maintenance fluids $(0.9 \%$ sodium chloride, $20 \mathrm{~mL} / \mathrm{hr}$ ) for the whole procedure. An arterial catheter (20 gauge) was placed in an ear artery to monitor blood pressure (Petas KMA 800, Ankara, Turkey) and arterial blood was sampled for gas analysis. Blood pressure was measured after the induction of anesthesia (preischemia), and 2 hours following the release of aortic cross clamping (postischemia) via the ear artery catheter. Arterial blood samplings measurements matched within the same time periods.

Animals were placed in the supine position. After sterile preparation, a 6- to 8-cm midline incision was made, and the superior mesenteric artery (SMA) and inferior mesenteric artery (IMA) was exposed through a transperitoneal approach with the abdominal contents reflected to the right. SMA and IMA were isolated from the left renal artery down to the aortic bifurcation. Each animal was given 150-U/kg heparin intravenously 5 minutes prior to SMA and IMA occlusion. Heparin was not reversed at the end of the procedure. In each rabbit, the SMA was isolated using atraumatic arterial bulldog clamps (Vascu-statt, Scanlan International, St. Paul, MN, USA). The ischemic phase was maintained with a complete occlusion of the SMA using atraumatic arterial bulldog clamps for 60 minutes, thereby interrupting the mesenteric blood flow. In all animals, except the sham controls ( $\mathrm{n}=8$ ), the SMA was crossclamped just proximal to the aortic bifurcation using atraumatic arterial bulldog clamps (Vascu-statt, Scanlan International, St. Paul, MN, USA) for 60 minutes. The IMA was also clamped at its origin from the aorta, and loss of aortic pulse was confirmed by palpation.

The clamp was removed after 60 minutes and restoration of blood flow was verified visually. Six hours after the intervention, all animals were humanely killed by a lethal cardiac injection of pentobarbital $(100 \mathrm{mg} / \mathrm{kg})$, immediately after which a median sternotomy was used to extract lung tissues for histopathological examination by light microscopy and biochemical investigations by MDA and MPO assay. The right lungs were removed, fixed with $10 \%$ tamponated formalin and stored for 24 hours. A sagittal section was obtained at the level of the hilum. These tissues were fixed again with $10 \%$ formalin for 2 days.

\section{HBO treatment procedure}

Animals received $\mathrm{HBO}$ therapy in an animal monoplace chamber during periods of 60 minutes of ischemia and 60 minutes of reperfusion at 2.5 times atmospheric pressure. Before pressurization, $100 \%$ medical oxygen was flushed through the chamber for 10 minutes to displace ambient air. The oxygen pressure was then increased slowly and reached 2.5 ATA in 5 minutes.

\section{Serum and tissue biochemical evaluation}

Blood $\mathrm{pH}, \mathrm{pO}_{2}(\mathrm{mmHg}), \mathrm{pCO}_{2}(\mathrm{mmHg})$, bicarbonate $\left(\mathrm{HCO}_{3}\right)$ 
$(\mathrm{mmol} / \mathrm{L})$ and lactate dehydrogenase (LDH) (IU/L) values were determined 1 hour after the onset of ischemia and 1 hour after the onset of reperfusion. Blood $\mathrm{pH}, \mathrm{pO}_{2}, \mathrm{pCO}_{2}, \mathrm{HCO}_{3}$, $\mathrm{Na}^{+}$and $\mathrm{K}^{+}$values were determined using a blood gas analyzer (Ciba Corning Blood Gas Analyzer Model 860, Ciba Corning Diagnostics Corp., Irvine, CA, USA). Plasma LDH levels were measured in lithium heparinized plasma using automated enzyme reactions (automated analysis for Hitachi System 717, Boehringer Mannheim Diagnostica, Mannheim, Germany).

\section{TNF- $\alpha$, sICAM-1, myeloperoxidase, and MDA assay}

TNF- $\alpha(\mathrm{pg} / \mathrm{mL})$ values were checked before ischemia, in the first hour of ischemia, and in the first and fourth hours of reperfusion; at the end of reperfusion period plasma and tissue MPA values, MDA values, and sICAM-1 levels were checked. TNF- $\alpha$ assays were performed according to the method described by Pizarro et al. [11] using the quantitative sandwich enzyme immunoassay technique (Quantikine M, R\&D Systems, Minneapolis, MN, USA). sICAM-1 levels were measured by single stage photometric enzyme immunoassay method. Lipid peroxidation in the lung tissue was evaluated by measuring the level of MDA, which is the end product of lipid peroxidation. MDA was measured in plasma and the lung as an indicator of free radicals. Plasma and tissue (lung) MDA levels were determined with spectrophotometry using thiobarbituric acid-reactive substances [12]. MPO, an enzyme found primarily within neutrophils, is a sensitive marker for quantifying neutrophil content in tissue. MPO activity, a sensitive marker of PML infiltration in tissues, was calculated by hydrogen peroxide dependent oxidation of tetramethylbenzidine, a reaction catalyzed by MPO [13].

\section{Histopathologic examination and lung neutrophil sequestration}

After standard tissue preparation, $5-\mu \mathrm{m}$ tissue sections were obtained. The specimens were stained with hematoxylin-eosin and examined with light microscopy (Eclipse E200; Nikon, Tokyo, Japan). All histopathological changes were detailed in each lung tissue, including inflammatory cell infiltration, alveolar edema, congestion, and preservation of the alveolar septum. At least 2 different sections were explored in each specimen. The same pathologist, who was blinded to the study, assigned a score of 0 to 4 on the basis of congestion, interstitial edema, polymorphonuclear leukocyte infiltration, and alveolar hemorrhage as follows: 0 , normal histological appearance; 1 , mild and focal changes; 2 , moderate and multifocal changes; 3 , marked and multi-focal changes; 4 , marked and diffuse changes. Additionally, to determine the severity of inflammation that resulted from IR process, leukocyte infiltration was scored semi quantitatively according to the following scale: 0 , no leukocyte infiltration; 1, <10 leukocytes; 2, 10-45 leukocytes; 3, >45 leukocytes (magnification <400) [14].

\section{Statistical analyses}

Data were analyzed using the SPSS ver. 10.0 (SPSS Inc., Chicago, IL, USA). All differences associated with a chance probability of 0.05 or less were considered statistically significant. All data are presented as mean \pm standard deviation. Statistical analysis was performed using analysis of variance (ANOVA) test. One-way ANOVA test was followed by post hoc Dunnett test.

\section{RESULTS}

\section{Physiological and hemodynamic parameters}

There were not any statistically significant differences among groups for physiological parameters in the pre- and postischemic periods. Table 1 presents $\mathrm{pH}, \mathrm{pO}_{2}, \mathrm{pCO}_{2}, \mathrm{HCO}_{3}$ levels. Blood $\mathrm{pH}, \mathrm{pO}_{2}$, and $\mathrm{HCO}_{3}$ were significantly lower in control group compared to sham and treatment groups. Blood $\mathrm{pO}_{2}$ concentration was significantly elevated in both $\mathrm{HBO}$ and $\mathrm{HBO}+\mathrm{IL}$ groups. There were not any significant differences in other parameters among $\mathrm{HBO}$, IL, and HBO + IL groups.

\section{TNF-a, sICAM-1, LDH, MPO, and MDA findings}

With regards to base (preoperative) TNF- $\alpha$ levels, no

Table 1. Blood $\mathrm{pH}, \mathrm{PO}_{2}, \mathrm{PCO}_{2}, \mathrm{HCO}_{3}$ levels determined at the end of the reperfusion period

\begin{tabular}{lcccc}
\hline \multicolumn{1}{c}{ Group } & $\mathrm{pH}$ & $\mathrm{pO}_{2}(\mathrm{~mm} \mathrm{Hg})$ & $\mathrm{pCO}_{2}(\mathrm{~mm} \mathrm{Hg})$ & $\mathrm{HCO}_{3}(\mathrm{mmol} / \mathrm{L})$ \\
$\mathrm{HBO}$ & $7.36 \pm 0.03$ & $265.8 \pm 37.2^{\mathrm{b})}$ & $40.6 \pm 4.50$ & $16.2 \pm 6.3$ \\
$\mathrm{IL}$ & $7.36 \pm 0.04$ & $115.7 \pm 16.5$ & $39.7 \pm 5.30$ & $17.4 \pm 9.2$ \\
$\mathrm{HBO}+\mathrm{IL}$ & $7.35 \pm 0.03$ & $247.09 \pm 25.3^{\mathrm{b})}$ & $37.8 \pm 4.08$ & $18.5 \pm 4.5$ \\
Control & $7.14 \pm 0.10^{\mathrm{a})}$ & $76.10 \pm 12.0$ & $48.4 \pm 6.3^{\mathrm{c})}$ & $8.72 \pm 7.0^{\mathrm{a})}$ \\
Sham & $7.40 \pm 0.02$ & $105.7 \pm 14.5$ & $34.2 \pm 4.20$ & $19.8 \pm 5.4$ \\
\hline
\end{tabular}

Values are presented as mean \pm standard deviation.

$\mathrm{HBO}$, hyperbaric oxygenation; IL, iloprost.

${ }^{\text {a) }}$ Significantly lower than the treatment groups by ANOVA test $(\mathrm{P}=0.005) .{ }^{\text {b) }}$ Significantly higher than the control, sham and IL groups by analysis of variance (ANOVA) test $(\mathrm{P}=0.001) .{ }^{\mathrm{c})}$ Significantly higher than the treatment groups by ANOVA test $(\mathrm{P}=0.002)$. 
significant differences were detected among the 5 groups ( $\mathrm{P}$ $=0.818$ ). At the end of 1,2 , and 4 hours, all three treatment groups showed a significant reduction in TNF- $\alpha$ increase when compared to the control group ( $\mathrm{P}=0.001)$. However, when the 3 treatment groups were compared to each other, the changes in TNF- $\alpha$ levels at the end of 1,2 , and 4 hours was not statistically significant $(P=0.398)$. Increase in TNF- $\alpha$ levels in every single group under medication is evaluated via Friedman test. In all three groups, a meaningful reduction in TNF- $\alpha$ levels of test subjects was observed ( $\mathrm{P}<0.001$ for all three groups) (Fig. 1). Plasma and lung MDA, MPO with plasma LDH, and sICAM-1 levels were significantly lower in the control group than those of $\mathrm{HBO}, \mathrm{IL}, \mathrm{HBO}+\mathrm{IL}$, and sham groups. Administration of IL and/or HBO inhibited MPO and MDA increase in plasma $(\mathrm{P}<$ 0.005 ) and in lung tissue $(\mathrm{P}<0.005)$ (Table 2).

\section{Light microscopic findings}

Histopathological results are shown in Table 3. Diffuse severe ischemic lung injury $(\mathrm{P}<0.001)$ the histopathological score $(\mathrm{P}<0.001)$ were significantly lower in the $\mathrm{HBO}, \mathrm{IL}, \mathrm{HBO}+\mathrm{IL}$, and sham groups when compared with the control group. Histopathological examination neutrophil sequestration was mostly detected in control group; while leukocyte infiltration in both sham and therapy groups was significantly lower than the control group (Fig. 2).

\section{DISCUSSION}

As the lungs and the liver have a considerable amount of macrophages, and are the primary organs in the recirculation pathway of translocated endotoxin, they are accepted as chief sources of TNF- $\alpha$. TNF- $\alpha$ is believed to be a main mediator included in controlling the flow of the inflammatory

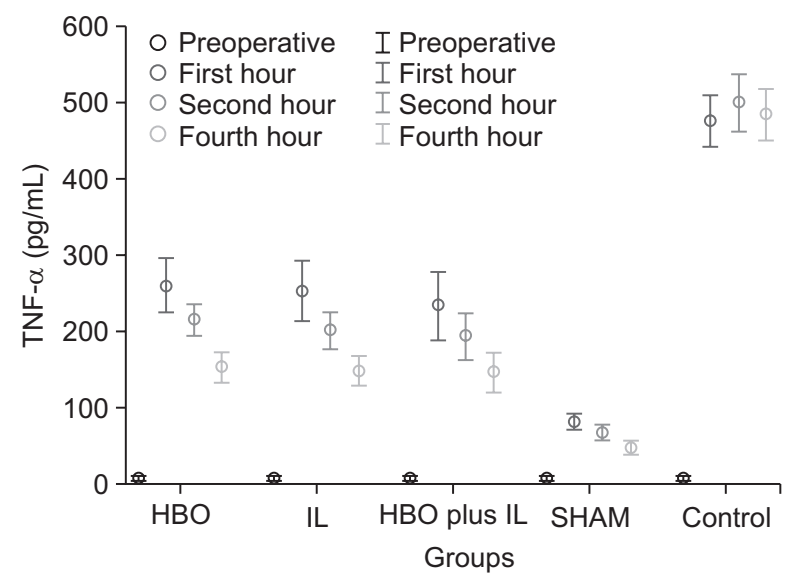

Fig. 1. Preoperative, serum tumor necrosis factor alpha (TNF- $\alpha$ ) levels in first hour of ischemia and first and fourth hours of reperfusion. HBO, hyperbaric oxygenation; IL, iloprost.

Table 2. Plasma and lung tissue MDA, MPO, sICAM-1 and LDH levels determined at the end of the reperfusion period

\begin{tabular}{lcccccc}
\hline \multicolumn{1}{c}{ Group } & $\begin{array}{c}\text { Plazma MDA } \\
(\mu \mathrm{mol} / \mathrm{L})\end{array}$ & $\begin{array}{c}\text { Lung MDA } \\
(\mu \mathrm{mol} / \mathrm{L})\end{array}$ & $\begin{array}{c}\text { Plazma sICAM-1 } \\
(\mathrm{ng} / \mathrm{mL})\end{array}$ & $\begin{array}{c}\text { Plazma MPO } \\
(\mathrm{U} / \mathrm{L})\end{array}$ & $\begin{array}{c}\text { Lung MPO } \\
(\mathrm{U} / \mathrm{g})\end{array}$ & $\begin{array}{c}\text { LDH } \\
(\mathrm{IU} / \mathrm{L})\end{array}$ \\
HBO & $32.6 \pm 2.3$ & $234.4 \pm 26.4$ & $2.4 \pm 0.3$ & $0.92 \pm 0.05$ & $1.8 \pm 0.5$ & $625.2 \pm 116.5$ \\
IL & $29.9 \pm 2.8$ & $220.6 \pm 22.3$ & $2.3 \pm 0.3$ & $0.76 \pm 0.02$ & $1.4 \pm 0.3$ & $607.4 \pm 134.2$ \\
HBO + IL & $24.3 \pm 2.2$ & $216.9 \pm 25.2$ & $2.1 \pm 0.3$ & $0.71 \pm 0.05$ & $1.6 \pm 0.5$ & $616.5 \pm 138.3$ \\
Control & $56.2 \pm 5.4^{\mathrm{a}, \mathrm{b})}$ & $432.7 \pm 46.7^{\mathrm{a}, \mathrm{b})}$ & $6.8 \pm 1.8^{\mathrm{a}, \mathrm{b})}$ & $2.78 \pm 0.5^{\mathrm{a}, \mathrm{b})}$ & $4.2 \pm 1.7^{\mathrm{a}, \mathrm{b})}$ & $796.3 \pm 167.2^{\mathrm{a})}$ \\
Sham & $18.3 \pm 2.1$ & $172.8 \pm 35.9$ & $1.1 \pm 0.3$ & $0 . .65 \pm 0.5$ & $0.9 \pm 0.02$ & $565.1 \pm 144.3$ \\
\hline
\end{tabular}

Values are presented as mean \pm standard deviation.

$\mathrm{HBO}$, hyperbaric oxygenation; IL, iloprost; MDA, malondialdehyde; MPO, myeloperoxidase; sICAM-1, circulating intercellular adhesion molecule-1; LDH, lactate dehydrogenase.

${ }^{\text {a) }} \mathrm{P}=0.001$ vs. Sham group. ${ }^{\text {b) }} \mathrm{P}=0.005$ vs. and treatment groups by analysis of variance test.

Table 3. Histopathologic results determined at the end of the reperfusion period

\begin{tabular}{lccccccc}
\hline Group & Grade 0 & Grade 1 & Grade 2 & Grade 3 & Grade 4 & Median (IQR) & $\begin{array}{c}\text { Neutrophil } \\
\text { sequestration }\end{array}$ \\
\hline HBO & 1 & 2 & 3 & 2 & - & $2(2)$ & $22.6 \pm 1.7$ \\
IL & 1 & 3 & 3 & 1 & - & $1(2.5)$ & $18.7 \pm 1.5$ \\
HBO + IL & 2 & 3 & 2 & 1 & - & $2(2)$ & $14.5 \pm 1.2$ \\
Control & - & 1 & 2 & 2 & 3 & $2(2)$ & $52.5 \pm 2.5$ \\
Sham & 3 & 3 & 2 & - & - & $2(3)$ & $6.2 \pm 0.8$ \\
\hline
\end{tabular}

Values are presented as mean \pm standard deviation unless otherwise indicated.

$\mathrm{IQR}$, interquartile range; $\mathrm{HBO}$, hyperbaric oxygenation; IL, iloprost. 

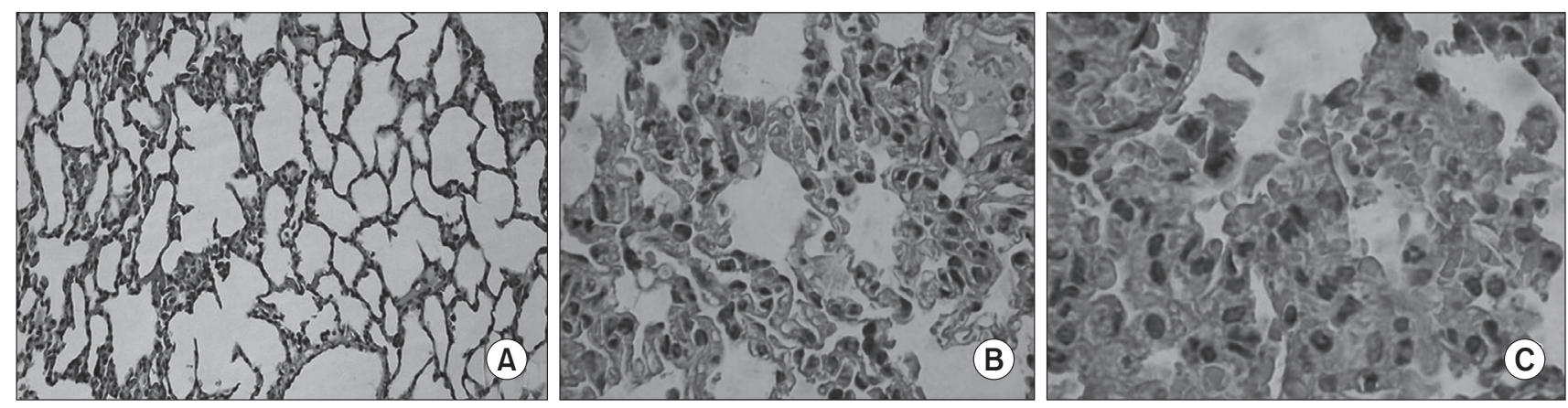

Fig. 2. (A) Lung tissue that does not show ischemic injury $(H \& E, \times 40)$. (B) Moderate degree of ischemic lung injury characterized by interstitial septal thickening, neutrophil infiltration, mild intra-alveolar edema and bleeding areas $(+)(\mathrm{H} \& \mathrm{E}, \times 200)$. (C) Diffuse, severe ischemic lung injury characterized by bleeding, edema, interstitial congestion, and neutrophil infiltration (H\&E, $\times 200$ ).

procedures that conduct IR mediated injury of the lung [15-18]. Okusawa et al. [17] reported that intravenous injection of TNF- $\alpha$ triggers comparable lung damage to IR induced lung damage. Colletti et al. [18] emphasized that anti-TNF- $\alpha$ antibodies have a protective effect against IR induced lung damage. Additionally, it has been reported that an increase in TNF- $\alpha$ levels was observed in cases of IR damage, and a rapid upregulation of adhesion receptors increasing the adhesion capabilities of TNF- $\alpha$ activated neutrophil and endothelial cells and an increase in respiratory macrophage degranulation resulting in oxidative tissue damage [19]. Yang et al. [20] held high TNF- $\alpha$ levels from intestinal IR induced lung damage responsible. In the present study, serum inspections after IR with lung damage revealed an enhance in MPO, sICAM-1, and TNF- $\alpha$ levels. Our findings support our thesis that TNF- $\alpha$ might be in charge for lung damage after aortic IR.

The decrease of neutrophil activation might lessen the occurrence of IR induced lung damage. This theory has been favored by research that has shown that the depletion of neutrophils improves IR induced injury of the lung. The advantageous outcomes of HBO might be attributable to its capability to decrease neutrophil activation and sequestration in IR injury. HBO might accomplish its favorable effects by conserving energy-rich compounds, restraining hypoxicischemic-induced lipid peroxidation, decreasing leukocyte adherence, reducing sequestration in reperfused tissue, and adjusting the inflammatory process [7,21]. In an animal study, HBO was shown to decrease arterial neutrophil concentration, but did not change lung neutrophil sequestration [22]. Tjarnstrom et al. [9] revealed a significant reduction in lung neutrophil sequestration in an intestinal IR rat animal model. The enrollment of lung neutrophils began throughout the interval of ischemia and endured for the period of reperfusion for a delayed period of time [23].

Intestinal IR persuades a general activation of neutrophils [22]. This is revealed by reports showing that HBO decreases neutrophil activation and releases intercellular adhesion molecule-1 [24,25]. Other mediators, i.e. decreased TNF- $\alpha$, might also be blamable. Kamada [26] revealed that rheumatoid arthritis patients treated with $\mathrm{HBO}$ accomplished a significant healing, proposing that $\mathrm{HBO}$ has an immunosuppressive effect. This is strengthened by animal studies in which HBO inhibits the production of IL-1 [27]. One current study has revealed that HBO reduces the production of TNF- $\alpha$, IL- 6 , and after immense hemorrhage [28]. Yang et al. [20] also reported that HBO hinders TNF- $\alpha$ production through IR damage.

IL acts as a membrane stabilizer and reduces neutrophils that are probable mediators of IR injury [16]. IL additionally reduces aggregation of white blood cells and vascular endothelium adhesion, superoxyde production from stimulated human neutrophils, and formation of free radicals in myocardium subjected to IR injury [16]. Since reduced microcirculation owing to the impairment of vascular endothelium of the lung documents a foremost pathologic characteristic, the prostanoids might be more efficient by altered properties such as leukocyte aggregation, platelet inhibition free radicals scavenging, and pulmonary vasodilatation $[7,16]$. In the present study, on test subjects treated with both $\mathrm{HBO}$ and IL not only a reduction in TNF- $\alpha$ levels but also a reduction in MPO and sICAM-1 levels is detected.

Rossman et al. [29] showed that mucosal and lung injury is reduced by perfusing the intestinal lumen with oxygenated perfluorocarbon during ischemia. Ueno et al. [30] revealed that $\mathrm{HBO}$ treatment following hepatectomy reduced activation of the neutrophils and enhanced the surgical outcomes. HBO should be given as quickly as possible throughout ischemia and reperfusion to gain a promising effect. Real time patient samples opting for therapeutic cardiovascular and cardiothoracic surgical modalities are also imperative to validate specific outcomes that will reveal critical insights as to a specific treatment regimen. However, results may not always hold good in difficult clinical scenarios where patients present 
with comorbidities such as smoking-induced lung collapse, chronic obstructive pulmonary disorders, type II diabetes mellitus, congenital abnormalities, and most importantly, non-small cell lung cancer. Therefore, it is important to design specific algorithms that will pave the way for the implication of effective and successful therapeutic strategies. In the present study, both $\mathrm{HBO}$ and IL were applied from the start of ischemia and positive effects were observed.

In conclusion, the present study has shown that both HBO and IL reduce the lung damage after aortic IR with regards to histopathological and biochemical aspects. This damage reduction effect of $\mathrm{HBO}$ and IL therapies was a result of reduced TNF- $\alpha$ production and reduced pulmonary neutrophil sequestration. Molecular cross-talks and interactions between different inflammatory cytokines will play a decisive role into disease pathogenesis and, therefore, it is extremely important to harness the effects of the same. Due to the experimental nature of the study, it is difficult to obtain conclusive long-term clinical implications. However, it is reasonable to speculate that through successful clinical trials in the future, it might be possible to ascertain therapeutic effects of $\mathrm{HBO}$ and IL for lung damage after aortic IR.

\section{CONFLICTS OF INTEREST}

No potential conflict of interest relevant to this article was reported.

\section{REFERENCES}

1. Bozok S, Kestelli M, Yurekli I, Guzeloglu M, Aksun M, Ortac R, et al. Local angioneogenetic effect of intramuscular interleukin-8 injection. Turkiye Klinikleri J Med Sci 2012;32:1273-7.

2. Firat O, Makay O, Yeniay L, Gokce G, Yenisey C, Coker A. Omega-3 fatty acids inhibit oxidative stress in a rat model of liver regeneration. Ann Surg Treat Res 2017:93:1-10.

3. Goldman G, Welbourn R, Klausner JM, Kobzik L, Valeri CR, Shepro D, et al. Mast cells and leukotrienes mediate neutrophil sequestration and lung edema after remote ischemia in rodents. Surgery 1992; 112:578-86.

4. Ozbek C, Kestelli M, Bozok S, Ilhan G, Yurekli I, Ozpak B, et al. Surgical stimulation of angiogenesis. Asian Cardiovasc Thorac Ann 2014:22:36-9.

5. Emrecan B, Tulukoglu E, Bozok S, Aksun M, Yağdi S, Ozcan AV, et al. Iloprost and pentoxifylline attenuate ischemiareperfusion injury in skeletal muscle in rabbit model. Ulus Travma Acil Cerrahi Derg 2008;14:182-7.

6. Bozok S, Ilhan G, Yilmaz Y, Dokumcu Z, Tumkaya L, Karamustafa H, et al. Protective effects of hyperbaric oxygen and iloprost on ischemia/reperfusion-induced lung injury in a rabbit model. Eur J Med
Res 2012;17:14.

7. Ilhan G, Aksun M, Bozok S, Ozpak HB, Gunes T, Durakoglugil ME, et al. Protective effects of hyperbaric oxygen and iloprost on ischemia-reperfusion injury in rabbit kidneys. Ital J Vasc Endovasc Surg 2013;20:89-95.

8. Ilhan G, Aksun M, Ozpak B, Gunes T, Bozok S, Durakoglugil ME, et al. The effect of combined hyperbaric oxygen and iloprost treatment on the prevention of spinal cord ischaemia-reperfusion injury: an experimental study. Eur J Cardiothorac Surg 2013;44:e332-40.

9. Tjarnstrom J, Wikstrom T, Bagge U, Risberg B, Braide M. Effects of hyperbaric oxygen treatment on neutrophil activation and pulmonary sequestration in intestinal ischemia-reperfusion in rats. Eur Surg Res 1999:31:147-54.

10. Emrecan B, Tulukoglu E, Bozok S, Kestelli M, Onem G, Kupelioglu A, et al. Effects of Iloprost and pentoxifylline on renal ischemia-reperfusion in rabbit model. Eur J Med Res 2006;11:295-9.

11. Pizarro TT, Malinowska K, Kovacs EJ, Clancy J Jr, Robinson JA, Piccinini LA. Induction of TNF alpha and TNF beta gene expression in rat cardiac transplants during allograft rejection. Transplantation 1993:56:399-404.
12. Mihara M, Uchiyama M. Determination of malonaldehyde precursor in tissues by thiobarbituric acid test. Anal Biochem 1978;86:271-8.

13. Tullis MJ, Brown S, Gewertz BL. Hepatic influence on pulmonary neutrophil sequestration following intestinal ischemiareperfusion. J Surg Res 1996;66:143-6.

14. Calikoglu M, Tamer L, Sucu N, Coskun B, Ercan B, Gul A, et al. The effects of caffeic acid phenethyl ester on tissue damage in lung after hindlimb ischemia-reperfusion. Pharmacol Res 2003:48:397-403.

15. Hidiroglu M, Uguz E, Ozerdem G, Yildiz E, Berkan O. The proinflammatory cytokine-mediated protective effects of pentoxifylline, iloprost, and cilostazol on a mitigating lung injury induced by lower limb ischemia and reperfusion in rats. Turk Gogus Kalp Dama 2014:22:138-44.

16. Naldan ME, Atalay C, Coskun A, Karaca M, Aydin Y, Dorman E, et al. The efficacy of spironolactone and surfactant treatment on HMGB1, CRP, IL- $1 \mathrm{~b}$ and TNF-a levels in acute lung injury. Turk Gogus Kalp Dama 2015;23:538-43.

17. Okusawa S, Gelfand JA, Ikejima T, Connolly RJ, Dinarello CA. Interleukin 1 induces a shock-like state in rabbits. Synergism with tumor necrosis factor and the effect of cyclooxygenase inhibition. J Clin 
Invest 1988;81:1162-72.

18. Colletti LM, Remick DG, Burtch GD, Kunkel SL, Strieter RM, Campbell DA Jr. Role of tumor necrosis factor-alpha in the pathophysiologic alterations after hepatic ischemia/reperfusion injury in the rat. J Clin Invest 1990;85:1936-43.

19. Mayer AM, Pittner RA, Lipscomb GE, Spitzer JA. Effect of in vivo TNF administration on superoxide production and PKC activity of rat alveolar macrophages. Am J Physiol 1993;264(1 Pt 1):L43-52.

20. Yang ZJ, Bosco G, Montante A, Ou XI, Camporesi EM. Hyperbaric O2 reduces intestinal ischemia-reperfusion-induced TNF-alpha production and lung neutrophil sequestration. Eur J Appl Physiol 2001;85:96-103.

21. Yamada T, Taguchi T, Hirata Y, Toyohara $T$, Hirose R, Suita S, et al. The effect of hyperbaric oxygenation on ischemiareperfusion injury of the small intestine. Transplant Proc 1994:26:1506-7.
22. Nahum A, Chamberlin W, Sznajder JI. Differential activation of mixed venous and arterial neutrophils in patients with sepsis syndrome and acute lung injury. Am Rev Respir Dis 1991;143(5 Pt 1):1083-7.

23. Kihara M, McManis PG, Schmelzer JD, Kihara Y, Low PA. Experimental ischemic neuropathy: salvage with hyperbaric oxygenation. Ann Neurol 1995;37:89-94.

24. Buras JA, Stahl GL, Svoboda KK, Reenstra WR. Hyperbaric oxygen downregulates ICAM-1 expression induced by hypoxia and hypoglycemia: the role of NOS. Am J Physiol Cell Physiol 2000;278:C292-302.

25. Cuzzocrea S, Imperatore F, Costantino G, Luongo C, Mazzon E, Scafuro MA, et al. Role of hyperbaric oxygen exposure in reduction of lipid peroxidation and in multiple organ failure induced by zymosan administration in the rat. Shock 2000; 13:197-203.

26. Kamada T. Superoxide dismutase and hyperbaric oxygen therapy of the patient with rheumatoid arthritis. Nihon Seikeigeka Gakkai Zasshi 1985:59:17-26.

27. Saito K, Tanaka Y, Ota T, Eto S, Yamashita U. Suppressive effect of hyperbaric oxygenation on immune responses of normal and autoimmune mice. Clin Exp Immunol 1991;86:322-7.

28. Yamashita M, Yamashita M. Hyperbaric oxygen treatment attenuates cytokine induction after massive hemorrhage. Am J Physiol Endocrinol Metab 2000;278:E8116.

29. Rossman JE, Caty MG, Zheng S, Karamanoukian HL, Thusu K, Azizkhan RG, et al. Mucosal protection from intestinal ischemia-reperfusion reduces oxidant injury to the lung. J Surg Res 1997;73:41-6.

30. Ueno S, Tanabe G, Kihara K, Aoki D, Arikawa K, Dogomori H, et al. Early postoperative hyperbaric oxygen therapy modifies neutrophile activation. Hepatogastroenterology 1999;46:1798-9. 